\title{
MAPEAMENTO DO FLUXO DE VALOR E SIMULAÇÃO PARA IMPLEMENTAÇÃO DE PRÁTICAS LEAN EM UMA EMPRESA CALÇADISTA
}

\section{VALUE STREAM MAPPING AND SIMULATION FOR IMPLEMENTATION OF LEAN MANUFACTURING PRACTICES IN A FOOTWEAR COMPANY}

\author{
Danilo Felipe Silva de Lima* E-mail: danilo.fslima@gmail.com \\ Paulo Guilherme de França Alcantara* E-mail: paulogfa@hotmail.com \\ Luciano Costa Santos* E-mail: luciano@ct.ufpb.br \\ Liane Márcia Freitas e Silva* E-mail: lianef@ct.ufpb.br \\ Ricardo Moreira da Silva* E-mail: ricardomoreira0203@hotmail.com \\ *Universidade Federal da Paraíba, João Pessoa, PB
}

\begin{abstract}
Resumo: Geralmente, a implementação do Lean Manufacturing (LM) se inicia com o Mapeamento do Fluxo de Valor (MFV). O objetivo deste trabalho é apresentar a aplicação do MFV, associado à simulação, a fim de analisar os impactos da adoção do LM no desempenho de uma empresa calçadista. Então, realizou-se um MFV do estado atual e, por meio da implantação de elementos da abordagem lean, pôde-se construir o MFV do estado futuro. Diferentes cenários foram simulados para a implementação do estado futuro e tiveram seus resultados comparados. As etapas produtivas simuladas foram o transfer, o corte e a montagem, visto que se considerou que entre esses processos poderia ser estabelecido um fluxo unitário do produto. Após a simulação, o cenário que apresentou melhores resultados proporcionou um aumento de produtividade de $19 \%$ em relação ao estado atual, além de melhoria em todas as outras variáveis que foram comparadas. A aplicação da simulação como um elemento adicional do MFV ajudou a identificar as vantagens da abordagem conjunta, uma vez que a mesma possibilita testar diferentes alternativas e definir melhor o estado futuro e suas estratégias de implementação.
\end{abstract}

Palavras-chave: Lean Manufacturing. Mapeamento do Fluxo de Valor. Simulação.

Abstract: The development of the Value Stream Mapping (VSM) is generally the first step for implementation of Lean Manufacturing (LM). The aim of this paper is to present an application of VSM with simulation in order to analyze the impacts of the LM adoption in the performance of a footwear plant. Therefore, a VSM was designed for the current state and, through the implementation of lean elements, a future state could be designed. Different scenarios were simulated for the future state implementation and the results were compared each other. Transfer, cutting and assembly sections were chosen to be simulated, because it was considered that would be possible to establish a onepiece flow between those processes. After the simulation, the scenario that presented the best results provided a $19 \%$ productivity increase over the current state, as well as improvement in all other process variables. The application of simulation as an additional element of VSM has helped to identify the advantages of the joint approach, since it enables to test different alternatives and better define the future state and its implementation strategies.

Keywords: Lean Manufacturing. Value Stream Mapping. Simulation. 


\section{INTRODUÇÃO}

Buscando aumentar sua vantagem competitiva por meio da gestão deoperações, muitas empresas recorrem ao Lean Manufacturing (LM), que tem por meta reduzir os desperdícios no processo para responder rapidamente à demanda do cliente. Para Bhamu e Sangwan (2014), o LM proporciona às organizações uma liderança competitiva através da redução de custos e melhoria da produtividade e qualidade.

Apesar do LM ser amplamente reconhecido por sua efetividade na melhoria contínua da produtividade, qualidade do produto e no sistema de entrega aos clientes, as organizações não estão explorando o completo potencial dos conceitos e técnicas inerentes à filosofia lean (LASA; CASTRO; LABURU, 2009). Uma das técnicas lean mais populares, porém ainda pouco explorada, é o Mapeamento do Fluxo de Valor (MFV), muito associado aos processos de implementação do lean. O MFV procura descrever o processo em seu estado atual para que, a partir da identificação de desperdícios, seja possível projetar um novo fluxo de valor para um estado futuro desejado.

Outra técnica que desponta no estudo do LM é a simulação de eventos discretos, que tem atraído a atenção de muitos pesquisadores e profissionais por permitir testar virtualmente cenários alternativos de soluções antes que as mesmas sejam implementadas fisicamente. Simular o sistema a ser estudado é um dos modos de reduzir custos no planejamento a fim de prever as diversidades e compreender a viabilidade técnica e econômica do que se pretende implementar. Historicamente, as empresas de manufatura são as maiores usuárias da simulação, devido à facilidade de uso e à pressão competitiva pela eficiência operacional, sendo a simulação de eventos discretos uma das técnicas mais úteis para modelagem e análise de problemas, utilizada para o planejamento, projeto e controle de sistemas complexos (GURUMURTHY; KODALI, 2011; OLIVEIRA; CORRÊA; NUNES, 2014).

Apesar de constituir uma técnica fundamental para o LM, a metodologia original de aplicação do MFV apresenta pontos frágeis que comprometem a sua eficácia. Em seu formato original, tal como foi proposto por Rother e Shook (2003), a transição entre o estado atual e o estado futuro é geralmente pobre em dados e está baseada na capacidade de abstração de cada analista. Do mesmo modo, a 
metodologia original não detalha adequadamente as alternativas para a implementação do estado futuro. Nesse sentido, a simulação de eventos discretos pode fornecer o complemento necessário para explorar todo o potencial do MFV como técnica central na implementação do LM. A simulação pode ajudar tanto a projetar diferentes cenários de estados futuros, quanto a detalhar alternativas para a implementação de um estado futuro projetado.

Contribuindo para a melhoria de um ponto frágil na metodologia de aplicação do MFV, este trabalho incorpora a simulação à técnica original e demonstra essa combinação por meio de um estudo realizado em uma fábrica que atua no setor calçadista. Nesse caso, a simulação de eventos discretos foi utilizada após a proposição de um estado futuro, buscando delinear caminhos para a implementação do mesmo por meio da aplicação de práticas lean ao processo estudado. O objetivo aqui não é demonstrar a aplicação das práticas lean, mas sim a aplicação da técnica de MFV que leva à implementação dessas práticas.

Este artigo está estruturado da seguinte forma: a Seção 1 contextualiza o trabalho e define seu objetivo. As Seções 2 e 3 abordam uma revisão da literatura acerca do Lean Manufacturing (LM) e do Mapeamento do Fluxo de Valor (MFV). A Seção 4 apresenta o método adotado para coleta e análise de dados. A aplicação do MFV, bem como a simulação dos cenários atual e futuros são apresentados na Seção 5. As considerações finais são encontradas na Seção 6.

\section{LEAN MANUFACTURING (LM)}

O conceito moderno do LM tem como marco o Sistema Toyota de Produção (STP), desbravado pelos engenheiros japoneses Taiichi Ohno e Shingeo Shingo. O Sistema Toyota foi desenvolvido pela Toyota Motor Corporation e aplicado em muitas empresas japonesas que, em virtude da crise do petróleo de 1973, passaram a adotar esta filosofia (BHAMU; SANGWAN, 2014; MONDEN, 2015).

Segundo Monden (2015), o Sistema Toyota é uma filosofia que tem por objetivo principal o lucro por meio da redução de custos ou aumento da produtividade, e esses fatores, por sua vez, são obtidos pela eliminação dos desperdícios, como o excesso de estoque e de pessoal. 
Pettersen (2009) comparou a literatura contemporânea e concluiu que não existe um consenso entre os autores sobre uma definição para o LM. Porém, neste artigo será adotado o conceito dado por Womack, Jones e Ross (1990), que definem - LM como um processo dinâmico de mudanças orientado por um conjunto sistemático de princípios e melhores práticas visando a melhoria contínua para a eliminação de desperdícios.

Um dos passos para se reduzir os custos operacionais é através da eliminação ou redução dos desperdícios, conhecido também pelo termo japonês Muda. Com o objetivo de facilitar a identificação dos desperdícios no processo produtivo, Shingo (1996) definiu sete categorias de desperdícios, apresentadas no Quadro 1.

Quadro 1 - Categorias de desperdícios

\begin{tabular}{|l|l|}
\hline Desperdício (Muda) & Conceito \\
\hline Superprodução & Produzir mais do que cliente necessita no momento. \\
\hline Espera & $\begin{array}{l}\text { Tempo ocioso pelo fato de materiais, pessoas, equipamentos ou } \\
\text { informações não estarem prontos. }\end{array}$ \\
\hline Transporte & Movimento do produto que não agrega valor. \\
\hline Processo & Esforço que não agrega valor do ponto de vista do cliente. \\
\hline Estoque & $\begin{array}{l}\text { Mais materiais, peças ou produtos disponíveis do que o cliente } \\
\text { necessita no momento. }\end{array}$ \\
\hline Movimentação & Movimento de pessoas que não agregam valor. \\
\hline Produtos defeituosos & $\begin{array}{l}\text { Trabalho que contém erros, retrabalho, enganos ou falta de algum } \\
\text { insumo necessário. }\end{array}$ \\
\hline
\end{tabular}

Fonte: Adaptado de Shingo (1996)

Monden (2015) afirma que os pilares do STP são o JIT (just-in-time) e a Autonomação. Para ele, os pilares proporcionam a uma organização estabelecer um fluxo contínuo de produção na empresa e na cadeia de suprimentos, e adaptar-se às variações da demanda. O JIT consiste em produzir a quantidade necessária no tempo necessário, enquanto que a Autonomação é interpretada como o controle autônomo de defeitos, apoiando o JIT ao não permitir que produtos defeituosos continuem seguindo no processo produtivo, o que prejudicaria a sincronização.

Para construir os pilares do STP, e consequentemente realizar a filosofia do LM, torna-se necessário um esforço conjunto para a implementação de práticas que 
se complementam ao formar o sistema lean. O Quadro 2 lista as definições de alguns técnicas, métodos e ferramentas lean.

Quadro 2 - Definições dos elementos do lean manufacturing

\begin{tabular}{|c|c|}
\hline $\begin{array}{l}\text { Técnicas/ } \\
\text { Métodos/Ferramentas }\end{array}$ & Definição \\
\hline Just-in-time (JIT) & $\begin{array}{l}\text { Significa basicamente produzir as unidades necessárias nas } \\
\text { quantidades necessárias dentro do tempo necessário. }\end{array}$ \\
\hline Kaizen & $\begin{array}{l}\text { São pequenas melhorias que ocorrem continuamente na organização } \\
\text { por meio da participação de todos, usando círculos de controle de } \\
\text { qualidade e sistemas de sugestões. }\end{array}$ \\
\hline Poka-yoke & $\begin{array}{l}\text { É um dispositivo introduzido na máquina ou na linha de produção que } \\
\text { previne produtos defeituosos, agindo como um dispositivo à prova de } \\
\text { erros. }\end{array}$ \\
\hline $\begin{array}{l}\text { Gestão da Qualidade Zero } \\
\text { Defeito (GQZD) }\end{array}$ & $\begin{array}{l}\text { Definido como o desenvolvimento, o projeto e a fabricação de produtos } \\
\text { que irão satisfazer as necessidades dos consumidores ao menor custo } \\
\text { possível. }\end{array}$ \\
\hline Layout celular & $\begin{array}{l}\text { A essência desse layout é o agrupamento de uma família de peças em } \\
\text { um fluxo linear, usualmente em forma de U. Geralmente conferem a } \\
\text { flexibilidade para se aumentar ou diminuir o número de trabalhadores } \\
\text { necessários para se adaptar às mudanças de demandas. }\end{array}$ \\
\hline Fluxo contínuo/unitário & $\begin{array}{l}\text { Consiste da introdução de cada unidade à linha, equilibrada pela } \\
\text { finalização de outra unidade de produto acabado, conforme } \\
\text { encomendado pelas operações dentro de um takt time. }\end{array}$ \\
\hline Takt time & $\begin{array}{l}\text { Consiste da produção e disponibilização de cada unidade de produto } \\
\text { em conformidade com o seu próprio intervalo de tempo dentro do qual } \\
\text { uma unidade do produto possa ser vendida em média. Considerado um } \\
\text { fator primordial para que haja sincronização da produção. }\end{array}$ \\
\hline Sistema kanban & $\begin{array}{l}\text { Sistema que gerencia o JIT, sendo um sistema de informações para } \\
\text { controle que permite puxar a produção em cada processo. }\end{array}$ \\
\hline $\begin{array}{l}\text { Troca Rápida de } \\
\text { Ferramentas (TRF) }\end{array}$ & $\begin{array}{l}\text { Técnica que viabiliza a redução dos tempos de setup. Para que ocorra a } \\
\text { redução desse tempo, deve-se planejar a conversão do setup interno } \\
\text { (atividades de preparação com a máquina parada) em setup externo } \\
\text { (atividades de preparação com a máquina em funcionamento). }\end{array}$ \\
\hline $\begin{array}{l}\text { Círculos de Controle de } \\
\text { Qualidade (CCQ) }\end{array}$ & $\begin{array}{l}\text { Consiste de pequenos grupos formados por trabalhadores que estudam } \\
\text { espontânea e continuamente conceitos e técnicas de controle de } \\
\text { qualidade a fim de oferecer soluções para problemas em seu local de } \\
\text { trabalho. }\end{array}$ \\
\hline
\end{tabular}

Fonte: Adaptado de Monden (2015)

Para implantar o LM é necessário entender a estrutura e o escopo dos sistemas de produção, definindo quais práticas devem ser adotadas. Enxergar o fluxo de informações e materiais através de toda a empresa e ter uma visão ampla, não apenas de processos individuais, são essenciais para a identificação e a eliminação dos desperdícios. Neste contexto, o Mapeamento do Fluxo de Valor se 
apresenta como umas das técnicas mais completas utilizadas no sistema lean (ABDULMALEK; RAJGOPAL, 2007).

\section{MAPEAMENTO DO FLUXO DE VALOR (MFV)}

O MFV é uma das técnicas do LM que pode ser usada dentro da fábrica, em uma família de produtos específica, bem como além das fronteiras da organização. Rosentrater e Balamuralikrishna (2006) apud Jasti e Sharma (2014) definem o MFV como uma técnica que identifica todas as atividades agregadoras de valor, bem como as não agregadoras, desde que a matéria-prima é entregue pelo fornecedor até ser transformado em produto acabado para entrega ao cliente. Segundo Serrano, Ochoa e Castro (2008) e Vinodh, Arvind e Somanaathan (2010), o MFV é uma análise detalhada dos materiais e informações que fluem através dos vários níveis de uma estrutura de produção. Isso permite identificar as fontes de desperdício e propor um estado futuro desejado que guiará a implementação do lean.

Em uma ampla revisão de literatura, Marodin e Saurin (2013) identificaram o Mapeamento do Fluxo de Valor como uma das técnicas mais utilizadas para a implementação do lean, apresentando o aumento de produtividade e a redução do lead-time como resultados típicos. Essa popularidade pode ser explicada pela facilidade de uso e pelo foco na implementação. Para Jasti e Sharma (2014), o MFV é uma importante técnica que auxilia os gerentes a entender as condições atuais de operação e a identificar as oportunidades para que seja possível melhorar o desempenho.

Rother e Shook (2003), pioneiros no MFV, apresentam uma metodologia de aplicação através de um fluxo da elaboração e desenvolvimento. A elaboração do MFV se inicia com a escolha de uma família de produtos, para a qual é desenhado o mapa do estado atual. Através de mapeamento faz-se a proposição de um estado futuro, que para ser alcançado necessita de um plano de ação delineado. Este plano de ação geralmente inclui a implementação de práticas lean para a melhoria do processo e eliminação de desperdícios. Por esse motivo, o MFV usualmente é considerado como ponto de partida para o lean. 
O MFV faz uso de diversos ícones específicos para os mapeamentos dos estados atual e futuro. Alguns desses ícones estão listados na Figura 1.

Figura 1 - Símbolos do MFV

ÍCONES DO FLUXO DE MATERIAL

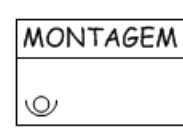

Processo

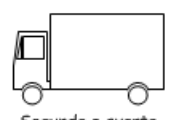

Segunda e quarta

Entrega via caminhão

Seta Empurrada

ÍCONES GERAIS

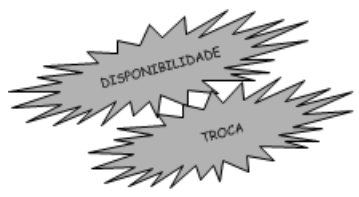

Necessidade de Kaizen

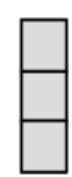

Pulmão ou Estoques de segurança

ÍCONES DO FLUXO DE INFORMAÇÃO
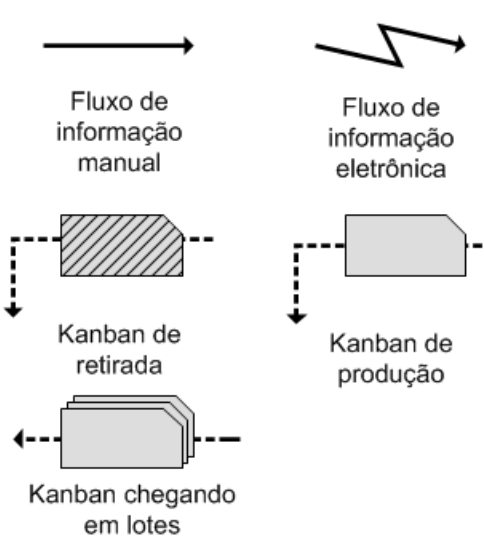

Fluxo de

informação eletrônica

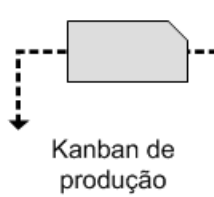

Fonte: Adaptado de Rother e Shook (2003)

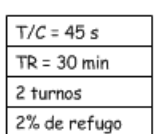

Caixa de dados

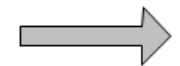

Produtos acabados para o cliente

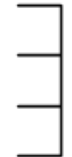

Supermercado

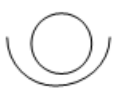

Operador

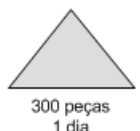

Estoque

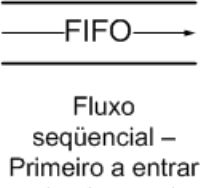

Primeiro a entrar primeiro a sair

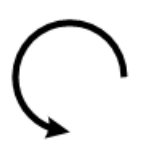

Retirada

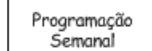

Informação

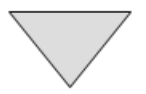

Kanban de

Sinalização

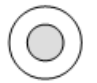

Bola para puxada sequenciada

\section{oxox}

Nivelamento de

carga

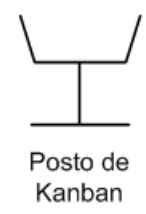

A partir dos resultados relatados na literatura, o MFV tem provado ser muito eficaz na identificação e eliminação de desperdícios. No entanto, a metodologia original de Rother e Shook (2003) ainda está sujeita a diversas críticas que sugerem 
uma melhor adequação de seu uso. Dal Forno et al. (2014), em sua pesquisa bibliográfica sobre a aplicação do MFV, identificou vários problemas relatados na implementação do MFV. Dentre os problemas identificados, os autores destacam a dificuldade que existe em alguns casos de medir dados do processo, o que resulta em visões muito otimistas ou muito pessimistas do processo, já que se baseia em uma "fotografia" do estado atual no momento em o mapeamento foi feito. Abdulmalek e Rajgopal (2007) argumentam que o projeto de um estado futuro no MFV frequentemente está baseado na "crença", com base na experiência de outras empresas, de que o desempenho vai melhorar. Porém, essa justificativa não é suficientemente convincente para muitos gerentes, que precisam de evidências quantitativas que realmente comprovem a viabilidade do estado futuro projetado.

Uma forma de inserir dinamismo ao MFV, em contraposição à abordagem estática de "fotografia" do estado atual, é incorporar a simulação de eventos discretos à técnica tradicional. De acordo com McDonald, Van Aken e Rentes (2002), a incorporação da simulação permite predizer dinamicamente indicadores de desempenho do processo como níveis de estoque e tempos de atravessamento. As vantagens da utilização conjunta do MFV com a simulação também são reconhecidas por Gurumurthy e Kodali (2011) e Oliveira, Corrêa e Nunes (2014), que propuseram modelos de simulação dentro do MFV tradicional.

O sucesso na utilização conjunta do MFV com a simulação de eventos discretos é confirmado por diversos exemplos encontrados na literatura, aplicados em diferentes contextos e com diferentes objetivos. Gurumurthy e Kodali (2011), por exemplo, aplicaram a simulação de eventos discretos para simular o estado atual e o estado futuro do MFV de um processo de fabricação de portas e janelas de PVC. Abdulmalek e Rajgopal (2007), por sua vez, utilizaram a simulação como uma maneira de quantificar os benefícios da aplicação de técnicas lean, via MFV, na indústria de processos contínuos. Com uma contribuição mais contundente, Lian e Van Landeghem (2007) desenvolveram um gerador de modelos de simulação para o MFV e o aplicaram em uma indústria de equipamentos destinados à criação de aves e suínos.

A integração da simulação com o MFV também tem sido explorada em aplicações menos convencionais, fora do ambiente de manufatura. Como exemplo, 
pode-se destacar o trabalho de Yang et al. (2015), que aplicaram MFV com simulação no processo de exame de sangue de um laboratório de análises clínicas, a fim de identificar atividades que não agregavam valor e propor melhorias ao processo. Em uma abordagem ainda mais inovadora, Ali, Petersen e França (2015) propuseram a combinação entre as duas técnicas para auxiliar no processo de desenvolvimento de software, simulando cenários alternativos para reduzir o tempo de desenvolvimento.

Os esforços para a integração entre simulação e MFV ajudam a preencher as lacunas deixadas pelo MFV original. É nesse sentido que este artigo propõe um esforço adicional nessa direção e demonstra isso por meio de um caso prático.

\section{PROCEDIMENTOS METODOLÓGICOS}

O estudo foi realizado em uma fábrica de sandálias de borracha de um grupo empresarial que atua no setor calçadista. De acordo com a tipologia de Cervo, Bervian e Silva (2007), neste trabalho foram utilizadas as seguintes técnicas de coleta de dados: observação direta assistemática, entrevistas informais, observação indireta e análise de documentos da empresa. As etapas da pesquisa estão descritas na Figura 2.

Figura 2 - Etapas da pesquisa

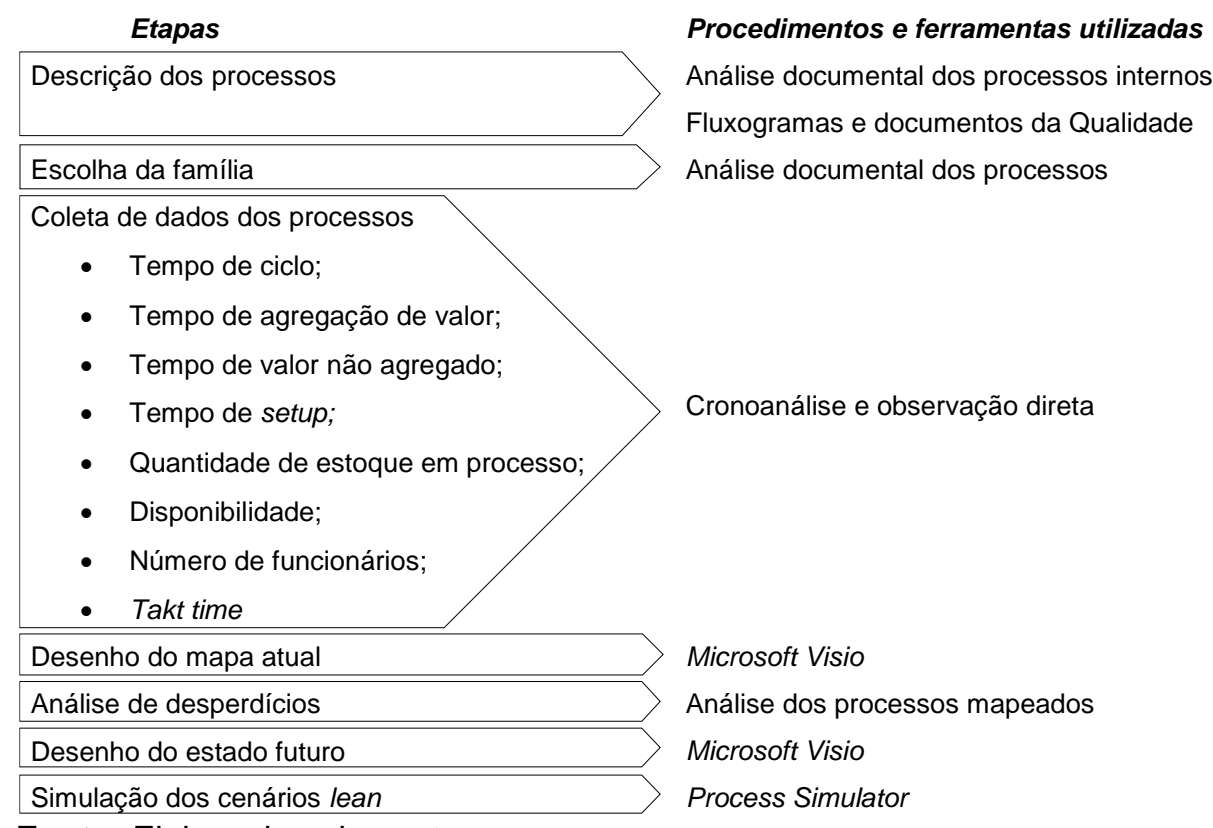

Fonte: Elaborado pelos autores

Revista Produção Online, Florianópolis, SC, v. 16, n. 1, p. 366-392, jan./mar. 2016. 
A observação direta assistemática foi realizada nos processos produtivos da empresa. Essa observação se caracterizou pela apreciação espontânea, informal, simples e ocasional das operações que constituíam os processos, com intuito de se obter as variáveis necessárias para o diagnóstico, a análise e a formulação de propostas de melhorias. Deste modo, foi feita a cronometragem de algumas variáveis como os tempos de ciclo, tempo de agregação de valor, tempo de não agregação de valor, tempo de troca dos processos. As quantidades de material em estoque intermediário e o tempo médio que esses estoques ficavam na fila foram observados diretamente no chão de fábrica.

Os dados gerais da empresa e dados referentes aos processos de apoio à produção foram coletados através de entrevistas informais com funcionários e gestores e análise de dados históricos dos processos produtivos analisados, com o objetivo de compreender e esclarecer os fatores e recursos de produção que influenciam no processo produtivo. Deste modo, foram levantados os dados de disponibilidade dos equipamentos e o número de operadores por processo.

Outra fonte de dados utilizada nesse estudo foi a observação indireta de registros de produção e análise dos documentos corporativos da empresa, como acompanhamentos de produção, fluxogramas, procedimentos operacionais dos processos e procedimentos corporativos da empresa. Essa análise indireta proporcionou um entendimento maior dos procedimentos, métodos, ferramentas e técnicas utilizadas pelos operadores na fabricação de sandálias.

Com base nos dados coletados foi possível elaborar o mapa do estado atual do processo de fabricação de sandálias e, posteriormente, o mapa do estado futuro. Para desenhar o mapa do estado atual, utilizou-se o programa Microsoft Visio, versão 2007, o qual já possui os ícones e símbolos do MFV.

Através da análise do estado atual foi possível enxergar alguns desperdícios que ocorrem em cada processo. Isto possibilitou a elaboração do mapa do estado futuro, com a proposta de implementação de práticas lean visando a redução e a eliminação desses desperdícios, bem como a transposição das barreiras contrárias à criação do fluxo enxuto.

Para a simulação do plano de ação e estado futuro, utilizou-se um aplicativo de extensão do próprio Microsoft Visio chamado Process Simulator, no qual foram 
testados via simulação os dados coletados sobre os processos estudados. Uma das limitações da aplicação da simulação neste estudo de caso é que não foi feita uma análise de sensibilidade do modelo gerado com uma validação estatística mais rigorosa. Essa limitação indica um caminho para a continuidade desta pesquisa, no sentido de aperfeiçoar a validação do estudo de simulação.

\section{ESTUDO DE CASO}

Por meio da metodologia de aplicação do MFV, foi analisado o estado atual do fluxo do processo analisado. O processo de fabricação das sandálias de borracha é basicamente composto por 6 processos: modelação da massa, prensagem da manta, estampa da arte na palminha (silk ou transfer), corte da palminha, injeção das tiras e montagem da sandália (Figura 3).

Figura 3 - Fluxo básico do processo

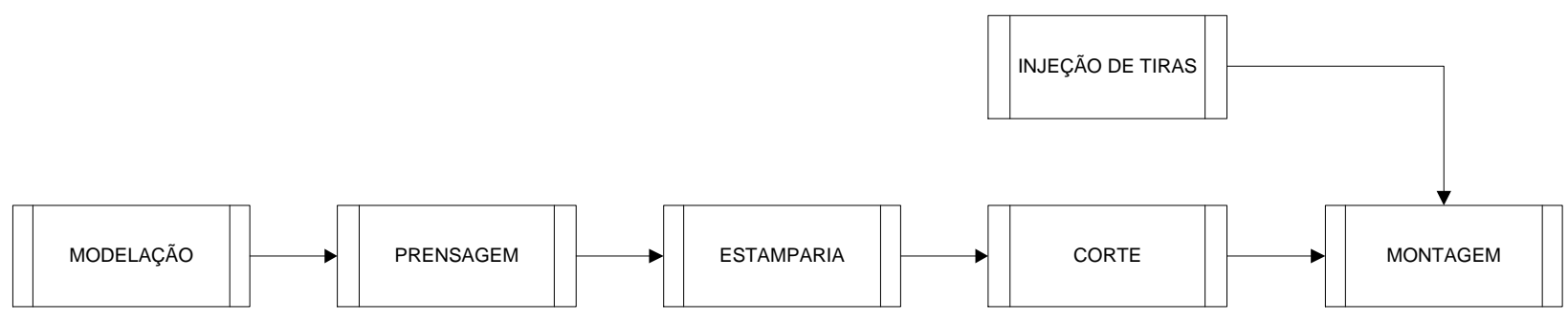

Fonte: Elaborado pelos autores

O processo de modelação se inicia com o recebimento da programação pelo operador, juntamente com as formulações referentes às especificações de palmilhas requisitadas pelos clientes (dureza, abrasão, resiliência, entre outros). O operador requisita ao almoxarifado os materiais necessários para a obtenção da massa solicitada. Após esse processo, são pesados os pigmentos, resinas e outras matérias-primas necessárias (de acordo com a formulação). Posteriormente, todas as matérias-primas são misturadas em um cilindro termicamente aquecido. $\mathrm{O}$ resultado desse processo caracteriza uma espécie de manta de borracha. Essa manta é modelada de acordo com as espessuras solicitadas. Depois a manta é resfriada, cortada em dimensões especificadas, pesadas e separadas em lotes (chamados de pesos) de acordo com as especificações requeridas para cada 
modelo e numeração. Os pesos são postos em carrinhos de transporte e movimentados para uma área de estocagem, onde aguardam para serem processados no estágio seguinte.

O processo de prensagem é onde a manta modelada recebe formas definitivas, obtendo-se as placas de borracha através da vulcanização/reticulação em moldes. Nesta etapa, os carrinhos com pesos são retirados da área de estocagem e colocados em fila em frente às prensas, de acordo com a sequência descrita na programação de produção. As mantas cortadas são então posicionadas na matriz (molde) dentro dos platôs (gavetas das prensas). Após isso, a prensa é fechada e ocorre a prensagem das mantas, que consiste no processo de vulcanização da borracha. Esse processo é determinado basicamente por dois parâmetros de processo: tempo e temperatura. Esses parâmetros irão determinar a expansão da borracha de acordo com as especificações previamente determinadas. Assim, depois de prensadas, as plaquetas de borracha são colocadas em uma área de resfriamento e estabilização onde aguardam, no mínimo, 24 horas para serem cortadas.

$\mathrm{Na}$ área de estabilização as placas são selecionadas e disponibilizadas para o corte. As placas em conformidade com as especificações requeridas são cortadas em um equipamento pneumático que pressiona uma navalha, com o formato do modelo de sandálias requerido, e faz o corte nas placas de borracha formando as palmilhas das sandálias. Cada placa de borracha, em condições ideais, produz três pares de sandálias. Depois de cortados, os pares são selecionados, verificados em relação à existência de possíveis defeitos e problemas de qualidade nas palmilhas, e separados em lotes (em caixas plásticas ou sacos plásticos) de acordo com a programação.

As palmilhas cortadas recebem a aplicação da arte no setor de estamparia, podendo ser serigrafadas, no caso do silk, ou aplicados adesivos e prensados termicamente, no caso do transfer. Nesta fase, as palmilhas são estampadas com artes customizadas (imagens, figuras ou textos) desenvolvidas para cada modelo. Os modelos são estampados de acordo com as especificações solicitadas pelos clientes. 
O processo de injeção de tiras se inicia com a pesagem das matérias-primas, dos quais os principais são PVC e pigmentos, referentes às especificações solicitadas pelos clientes. De acordo com a formulação, as matérias-primas e os pigmentos são misturados e acondicionados em recipientes, formando uma mistura com todas as matérias-primas. Depois as máquinas injetoras são abastecidas com essa mistura e se inicia o processo de injeção das tiras nos moldes. Posteriormente, as tiras são retiradas dos moldes em forma de "cachos". As tiras são destacadas dos cachos, separadas de acordo com a numeração e modelo, colocadas em caixas de plástico, identificadas e disponibilizadas para a mesa de montagem.

$\mathrm{Na}$ mesa de montagem é realizada a montagem das tiras e aviamentos nas palmilhas. O processo de montagem se inicia com o recebimento da programação, onde estarão descritos todos os componentes das sandálias a serem montados. Após a liberação dos lotes, as palmilhas passam por um processo de escariação, no qual se faz o alargamento do orifício onde a tira será colocada. Em seguida, as tiras são montadas nas sandálias. Faz-se então uma inspeção visual das sandálias, limpeza dos pares em conformidade e separação dos produtos não conformes. Depois de limpos são fixados, nos pares em conformidade, os aviamentos solicitados pelos clientes (etiquetas, cabides, acessórios, entre outros). Por fim, os pares liberados são agrupados de dez em dez pares, de acordo com a programação, e guardados em caixas de papelão, onde serão disponibilizados para a expedição.

\subsection{Escolha da família de produtos}

Seguindo a metodologia de aplicação do MFV, a primeira etapa realizada foi a escolha das famílias de produtos. A indústria calçadista segue períodos de tendência e da moda, gerando uma grande variabilidade de modelos e produtos. Quanto aos modelos e aos produtos, as sandálias variam de cliente para cliente (grandes marcas que terceirizam a produção), assim como um modelo pode variar em cores e tamanhos.

Basicamente todos os processos são iguais para todos os modelos de sandálias, mas podem-se identificar duas famílias: silk e transfer. O que distingue as 
duas famílias é o modo como a arte ou o desenho é estampado na palmilha. Esse trabalho foi concebido tomando base a análise de sandálias da família transfer.

\subsection{Mapa do estado atual}

O próximo passo da metodologia foi o registro do estado atual do processo (Figura 4). Para o desenho do mapa do estado atual foram coletados os dados de mercado e dados internos do processo produtivo.

Figura 4 - Mapa do estado atual

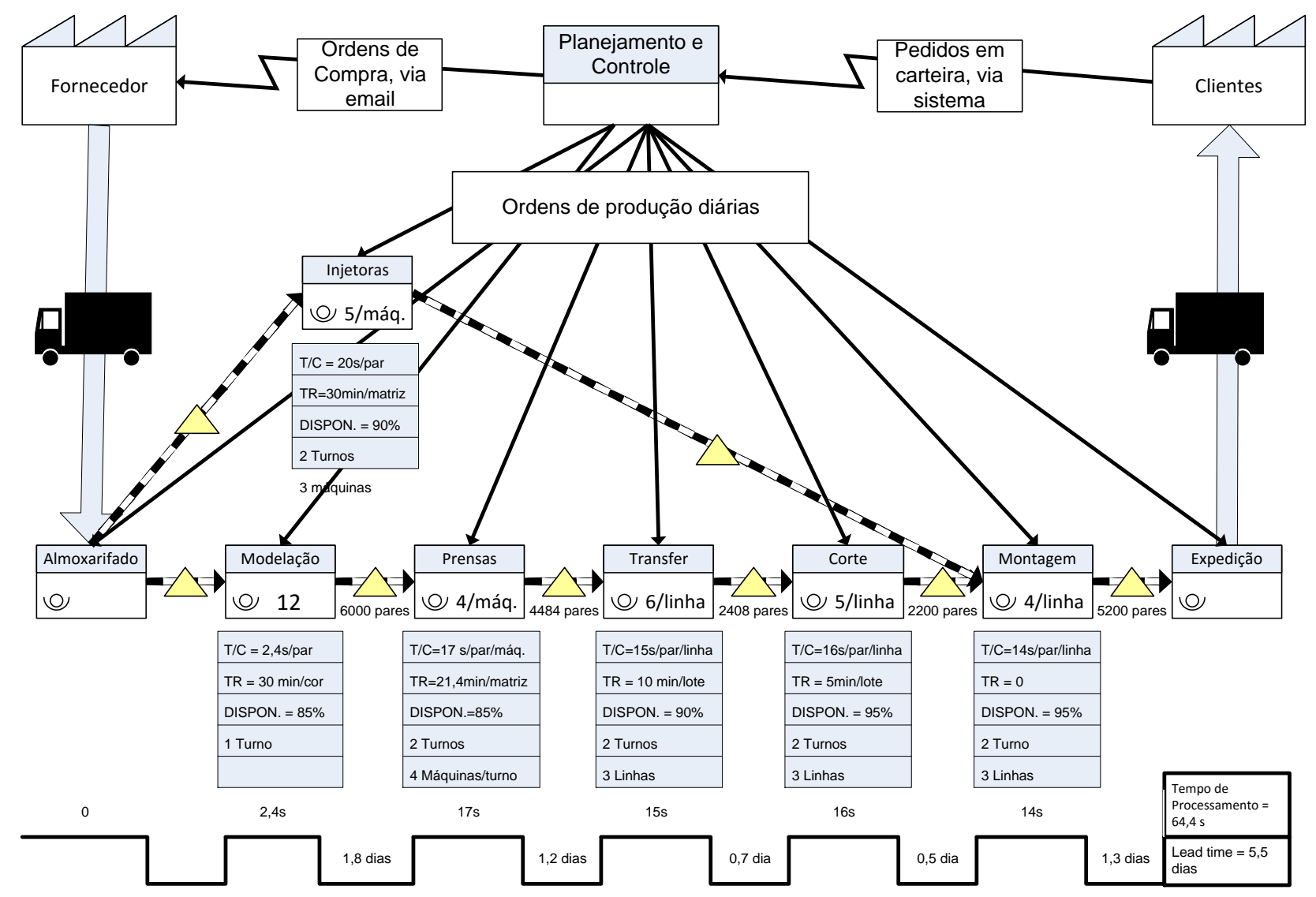

Fonte: Elaborado pelos autores

O fluxo de materiais na produção é realizado de forma empurrada, no qual cada etapa produz o que foi planejado, não se preocupando se o estágio posterior necessita ou não daquele material, ocasionando altos estoques intermediários antes e depois de cada processo. No entanto, problemas com fornecedores, problemas de qualidade dos produtos e problemas de sincronização da produção (principalmente 
na montagem das sandálias, que necessitam das palmilhas, tiras e aviamentos disponíveis no tempo certo) geram altos índices de desperdícios e muito retrabalho.

Na Figura 4, abaixo do fluxo de material está desenhada a linha do tempo. A partir da análise dos tempos, é possível enxergar que o tempo de ciclo acumulado para que o produto seja processado em todas as operações é de 64,4 segundos, enquanto que, o tempo de atravessamento de um produto na empresa (porta a porta) é de aproximadamente 5,5 dias.

Considerando o mapa do estado atual e a observação direta dos processos, identificou-se os principais desperdícios e suas respectivas causas, listados no Quadro 3.

A partir da análise dos processos e da determinação dos desperdícios, foi possível identificar as atividades que agregam valor e as que não agregam valor algum ao produto. A Figura 5 mostra uma comparação do tempo de agregação de valor (TAV) e o tempo de não agregação de valor (TNAV) de cada processo produtivo. Os dados mostram que muito do tempo gasto atualmente nos processos é consumido por atividades que não agregam valor aos produtos, e por sua vez, só geram custos.

Observa-se na Figura 5 que os tempos de agregação TAV dos processos de modelação, prensagem e injeção de tiras superam o TNAV, sendo 80,00\%, 85,71\% e 64,29\%, respectivamente, do tempo de ciclo de cada processo. Esses processos apresentam um alto grau de automatização de máquinas em comparação com os outros processos. Por outro lado, os processos de transfer, corte e montagem são muito dependentes de trabalhos manuais e pouco automatizados. Nesses processos observam-se baixos tempos de agregação de valor 46,57\%, 51,01\% e 50,08\%, respectivamente a corte, transfer e montagem. Deste modo, esses processos apresentam maior necessidade de melhorias e demandam maiores esforços que serão focalizados no mapa do estado futuro. 
Quadro 3 - Fontes de desperdícios existentes no processo

\begin{tabular}{|c|c|c|}
\hline Processo & Desperdícios & Análise \\
\hline Modelação & $\begin{array}{l}\text { - Superprodução } \\
\text { - Espera } \\
\text { - Movimentos } \\
\text { desnecessários }\end{array}$ & $\begin{array}{l}\text { Na Figura } 4 \text { observam-se grandes estoques intermediários após o } \\
\text { processo de modelação, que contabilizam } 6 \text { mil pares de sandálias. Essa } \\
\text { quantidade fica estocada, em média, 1,8 dias antes de ser processada } \\
\text { nas prensas. Os desperdícios de espera estão relacionados com o } \\
\text { tamanho dos lotes, chamados de pesos. Enquanto a manta está sendo } \\
\text { cortada, os primeiros materiais cortados aguardam até que se complete o } \\
\text { peso (aproximadamente } 150 \text { pares), só depois eles são disponibilizados } \\
\text { para o processo posterior. Essa espera não agrega valor ao produto e } \\
\text { contribui para a ocorrência de movimentos desnecessários dos } \\
\text { operadores. }\end{array}$ \\
\hline \multirow[t]{2}{*}{ Prensagem } & $\begin{array}{l}\text { - Espera } \\
\text { - Superprodução } \\
\text { - Estoques } \\
\text { - Movimentos } \\
\text { desnecessários }\end{array}$ & $\begin{array}{l}\text { Devido ao tempo de troca das matrizes ser alto, geralmente são } \\
\text { produzidas grandes quantidades de produtos para evitar ao máximo o } \\
\text { tempo de máquina parada. Itens são produzidos mais cedo e em maiores } \\
\text { quantidades do que o cliente necessita. Isso faz gerar grandes estoques, } \\
\text { que ocupam espaço físico no chão de fábrica, despendem tempo dos } \\
\text { trabalhadores para carregar (armazenar, movimentar) os materiais sem } \\
\text { necessidade, entre outras atividades improdutivas. }\end{array}$ \\
\hline & $\begin{array}{l}\text { - Elaboração de } \\
\text { produtos } \\
\text { defeituosos }\end{array}$ & $\begin{array}{l}\text { O processo de prensagem gera muitos produtos defeituosos. Isso se dá } \\
\text { principalmente pelo estado de conservação das prensas e por } \\
\text { contaminação da massa. Isso acarreta em desperdícios de material, de } \\
\text { disponibilidade de mão-de-obra e equipamentos, entre outros. }\end{array}$ \\
\hline Injeção de tiras & $\begin{array}{l}\text { - Superprodução } \\
\text { - Estoques } \\
\text { - Espera } \\
\text { - Movimentos } \\
\text { desnecessários }\end{array}$ & $\begin{array}{l}\text { A falta de sincronização de produção do processo de injeção com o } \\
\text { processo de estampa de artes nas palmilhas faz com que se produzam } \\
\text { grandes quantidades de tiras, a fim de evitar o risco de que a montagem } \\
\text { pare por falta de tiras. Assim, a produção de tiras é realizada sem que se } \\
\text { tenha noção de quanto e quando produzir. Os lotes esperam longos } \\
\text { períodos de tempo estocados até serem solicitados pelos clientes, na } \\
\text { montagem. Além disso, isso gera movimentos desnecessários e ocupa os } \\
\text { operadores com atividades que não agregam valor. }\end{array}$ \\
\hline \multirow[t]{2}{*}{ Corte } & $\begin{array}{l}\text { - Superprodução } \\
\text { - Estoque } \\
\text { - Espera } \\
\text { - Movimentos } \\
\text { desnecessários }\end{array}$ & $\begin{array}{l}\text { As plaquetas de borracha são cortadas pelos operadores par por par, } \\
\text { posteriormente os pares são revisados e selecionados, e por fim são } \\
\text { estocados. Os materiais estocados ocupam uma grande área na planta, } \\
\text { dificultando a movimentação de pessoas e o transporte de materiais. } \\
\text { Outro desperdício visualizado nesse processo é a espera. Esse } \\
\text { desperdício está relacionado com o tamanho dos lotes ( } 480 \text { pares) e o } \\
\text { tempo que o material fica na fila antes de um processo esperando para } \\
\text { ser processado. Com o excesso de estoques, os operadores se } \\
\text { movimentam desnecessariamente para o manuseio dos lotes. }\end{array}$ \\
\hline & $\begin{array}{l}\text { - Elaboração de } \\
\text { produtos } \\
\text { defeituosos }\end{array}$ & $\begin{array}{l}\text { A exigência pela velocidade imposta e a má qualidade e/ou a falta de } \\
\text { manutenção das navalhas resulta em muitos defeitos e problemas de } \\
\text { qualidade nos produtos, ocasionando muito retrabalho no processo. }\end{array}$ \\
\hline Transfer & $\begin{array}{l}\text { - Superprodução } \\
\text { - Estoque } \\
\text { - Espera } \\
\text { - Movimentos } \\
\text { desnecessários }\end{array}$ & $\begin{array}{l}\text { A falta de sincronização do processo de montagem contribui para o } \\
\text { processamento de grandes quantidades de palmilhas antes de serem } \\
\text { realmente necessárias. O desperdício de espera ocorre com as palmilhas, } \\
\text { que depois de passarem pelo processo em que as artes são estampadas, } \\
\text { são novamente loteados e estocados antes da mesa de montagem. Os } \\
\text { primeiros pares do lote esperam até que o lote seja completado e depois } \\
\text { aguardam na fila até serem solicitados na mesa de montagem. Neste } \\
\text { processo observam-se grandes quantidades de estoques anteriores e } \\
\text { posteriores. Os operadores gastam tempo excessivo procurando o } \\
\text { material para ser processado na fila e depois para depósito e } \\
\text { organização. }\end{array}$ \\
\hline Montagem & $\begin{array}{l}\text { - Espera } \\
\text { - Movimentos } \\
\text { desnecessários }\end{array}$ & $\begin{array}{l}\text { Os componentes esperam muito tempo na fila até serem liberados para a } \\
\text { mesa de montagem. Depois que os componentes são liberados para } \\
\text { montagem os funcionários têm que puxar as caixas plásticas com os lotes } \\
\text { e organizá-los na ordem que serão montadas antes da mesa de } \\
\text { montagem. Muitos movimentos realizados pelos operadores durante a } \\
\text { montagem das sandálias são improdutivos e não agregam valor ao } \\
\text { produto. }\end{array}$ \\
\hline
\end{tabular}

Fonte: Elaborado pelos autores

Revista Produção Online, Florianópolis, SC, v. 16, n. 1, p. 366-392, jan./mar. 2016. 
Figura 5 - Comparativo TAV versus TNAV

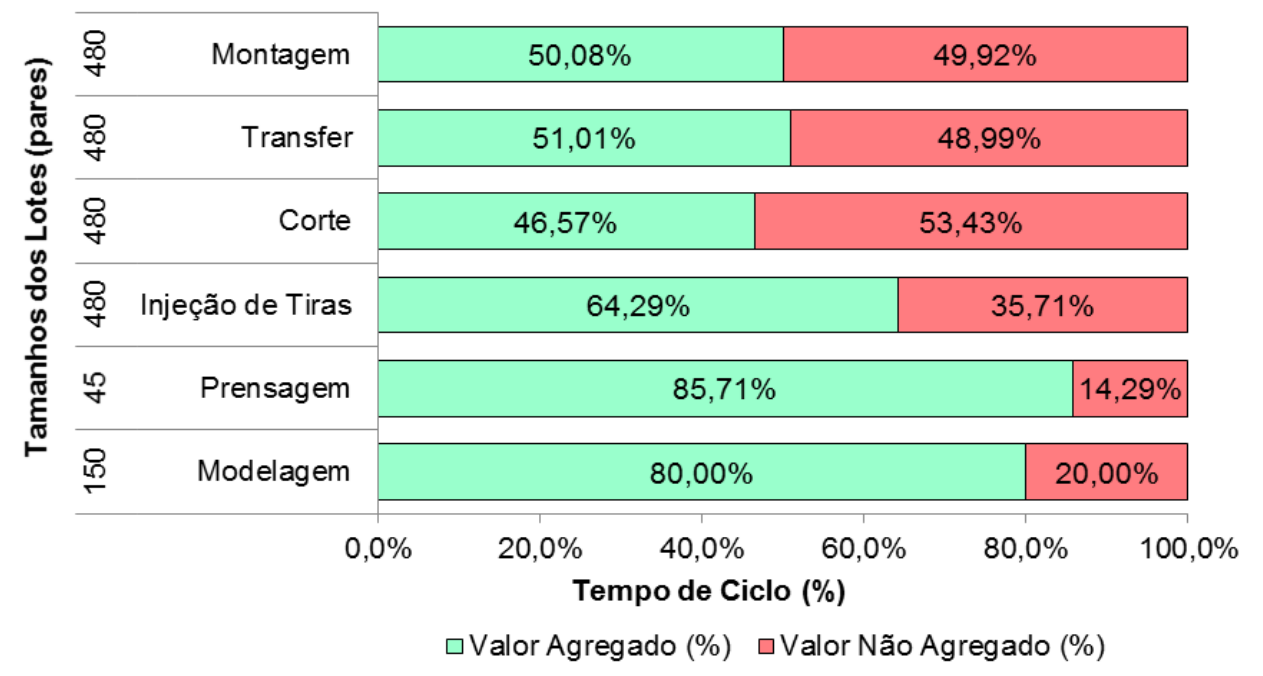

Fonte: Elaborado pelos autores

\subsection{Mapa do estado futuro}

De acordo com as características da família e do processo, foi possível desenhar um estado futuro, respeitando as restrições e a tecnologia atual da empresa. $O$ estado futuro (Figura 6 ) focalizou 0 combate aos estoques intermediários, criando fluxo unitário onde era possível e supermercados (estoques controlados) onde os tempos de ciclo não poderiam ser sincronizados de acordo com o takt time.

Para cálculo do takt time foi obtido junto ao departamento comercial a quantidade de produtos requeridos pelo mercado e, junto à engenharia industrial, foram coletados os dados relativos à disponibilidade dos recursos produtivos. $\mathrm{O}$ cálculo gerou um takt time de 5,6 s/par, que serviu como parâmetro para o novo projeto do fluxo.

As prensas são reconhecidamente o gargalo do sistema e demandam 2 turnos e 4 máquinas para atender à demanda. Devido ao elevado tempo de setup, as prensas também ditam o ritmo dos processos anteriores e posteriores a elas. Deste modo, no estado futuro idealizado elas representam o último processo puxador. Esse processo será responsável para receber a programação do PCP e puxar as quantidades necessárias para atender a demanda. A retirada do kanban entre os processos de prensas e modelação irá iniciar o processo anterior que irá produzir nas quantidades e produtos requeridos. Pela característica intrínseca dos 
processos e dos diferentes tempos de ciclo é necessário o dimensionamento de um supermercado entre eles, que foi dimensionado um supermercado de 1,8 dias. Do mesmo modo acontece no pós-prensa, onde os fluxos não podem ser sincronizados e foi criado um supermercado de 1,2 dias.

Figura 6 - Mapa do estado futuro

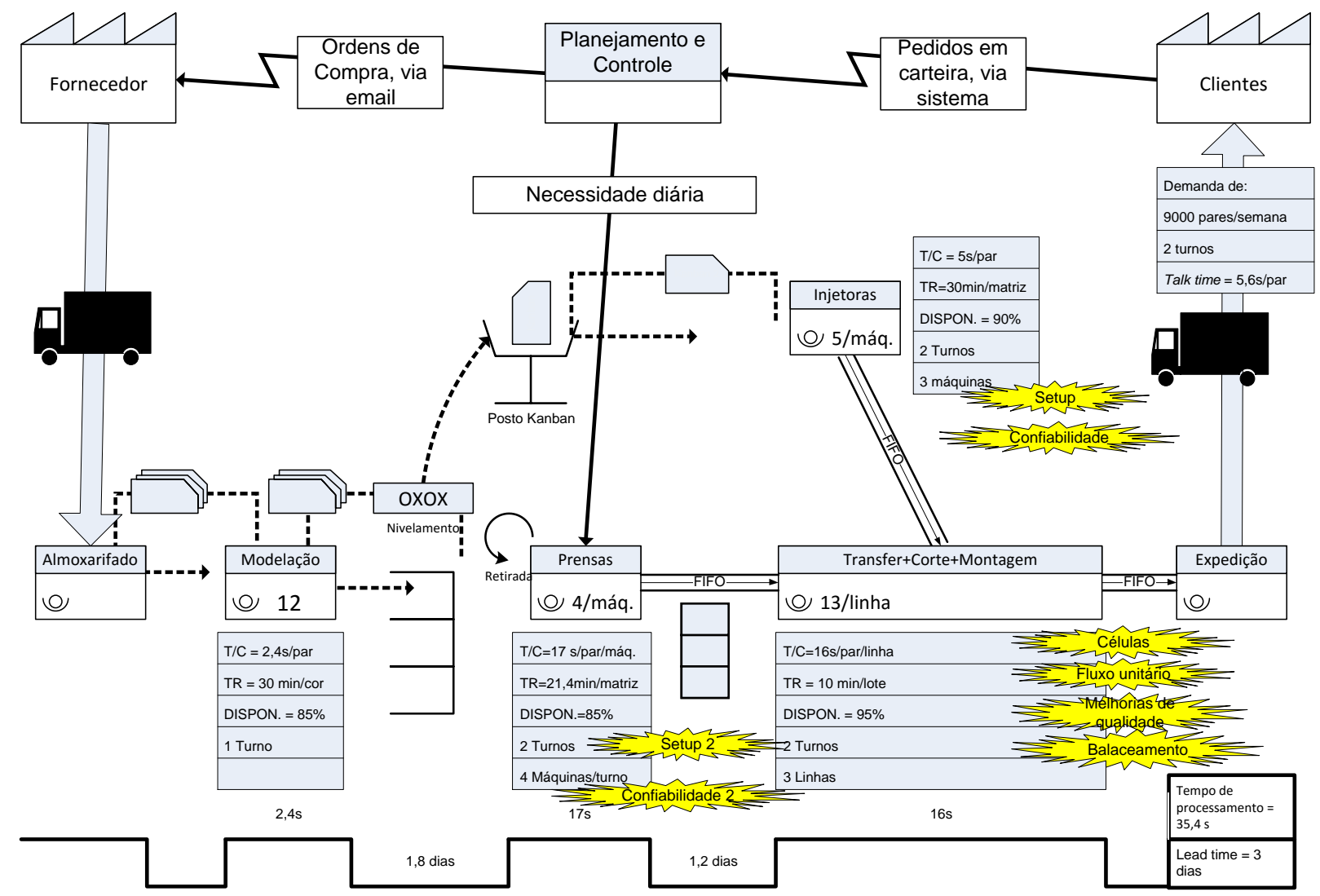

Fonte: Elaborado pelos autores

A modelagem tem o tempo de ciclo menor e demanda apenas 1 turno para atender o takt time. Como explicitado anteriormente, as ordens de produção são agregadas nesse processo para diminuir as quantidades de setup e aumentar a utilização do equipamento que consome muitos recursos (pessoas, energia elétrica e material).

Para alcançar o estado futuro, a principal mudança observada é o rearranjo físico dos processos de transfer, corte e montagem, em que se prevê a criação de uma célula. O rearranjo foi considerado viável, visto que as atividades componentes do processo apresentam tempos de ciclo equivalentes. 
Com a adoção do layout celular é possível a criação do fluxo unitário de peças. Os lotes que eram transferidos em quantidades de 480 pares, passam a fluir pelos processos de forma empurrada seguindo um fluxo unitário e obedecendo ao sequenciamento a FIFO (first in, first out). A Figura 7 mostra a proposta de linearização dos processos e os postos de trabalho projetados.

Figura 7 - Proposta de linearização celular para transfer, corte e montagem

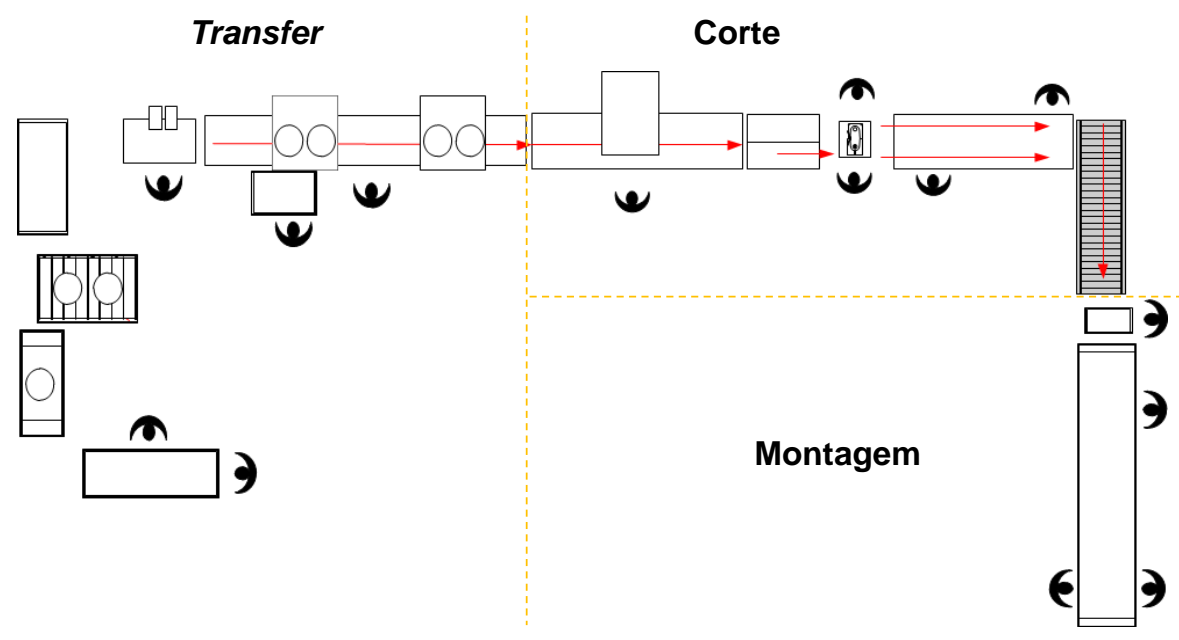

Fonte: Elaborado pelos autores

A proposta tende a automatizar o processo através de esteiras horizontais que transportam o material até o posto de trabalho sem que haja necessidade de movimentação do operador, além de proporcionar a sincronização do fluxo. Para atender à demanda ditada pelo cliente, os processos foram balanceados através do tempo de ciclo e da utilização de linhas e turnos extras para suprir a necessidade demandada.

\subsection{Simulação da implementação}

Analisando os desperdícios identificados, observam-se grandes oportunidades de melhorias no processo para criação do fluxo enxuto pela eliminação das atividades que não agregam valor ao produto. Assim, foi construído um modelo simplificado do processo no Process Simulator e testado em cenários diferentes (Figura 8). Os processos simulados foram o transfer, o corte e a montagem, considerando o projeto de um fluxo unitário do produto. A intenção foi 
observar os potenciais resultados das melhorias propostas através da aplicação dos conceitos lean e, por meio da simulação, observar o comportamento do processo em relação às ações de melhorias idealizadas.

Figura 8 - Modelo construído no Process Simulator

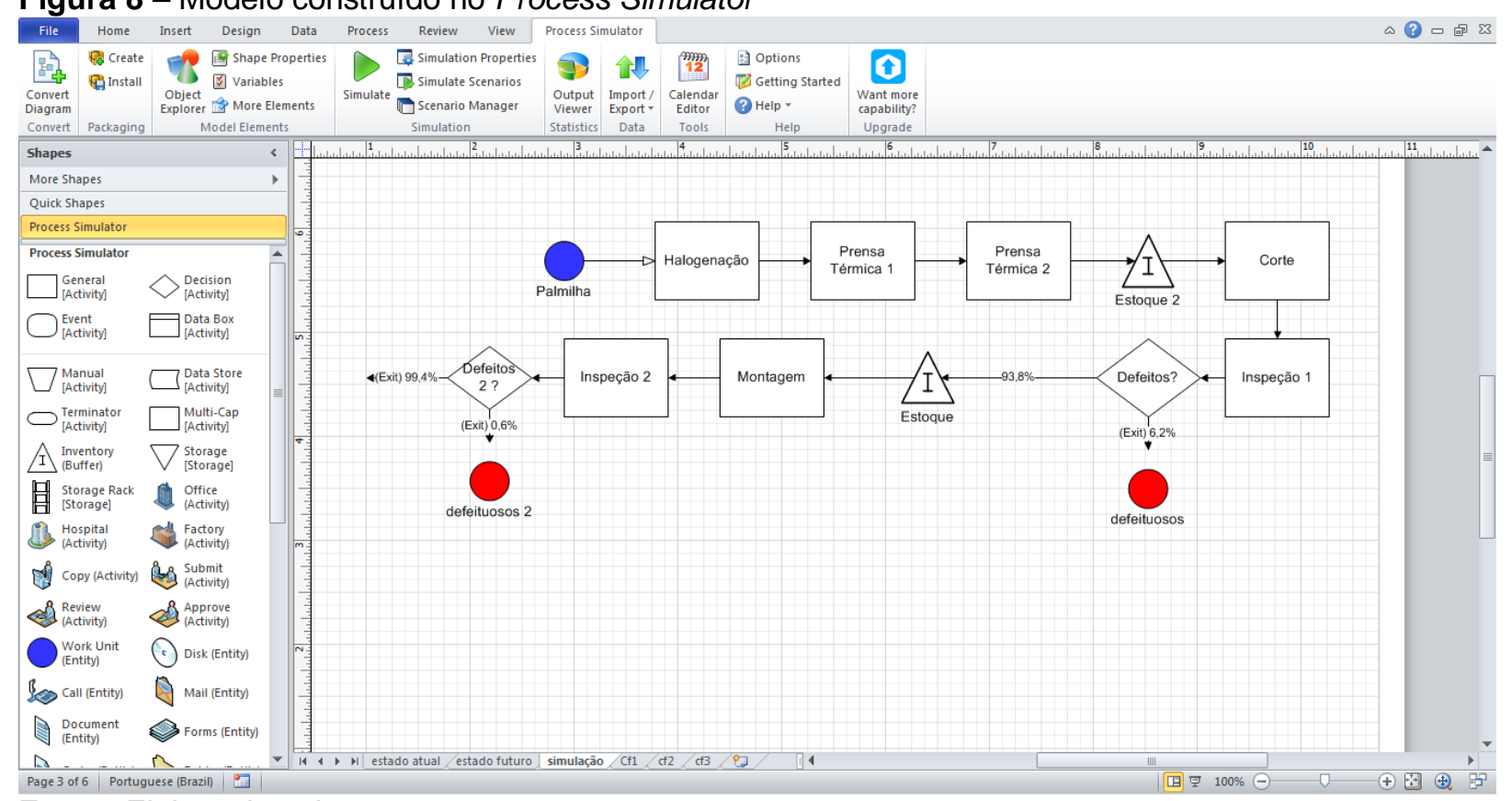

Fonte: Elaborado pelos autores

Para alcançar o estado futuro idealizado foram construídos e simulados três cenários distintos (Cf1, Cf2 e Cf3), descritos no Quadro 4, que podem ser vistos como os passos sequenciais para chegar ao mapa futuro idealizado nessa proposta. Portanto, os cenários simulados são cumulativos, em que os cenários seguintes incorporam a melhoria dos cenários anteriores.

Os dados utilizados na simulação foram obtidos através dos registros históricos dos processos e dos tempos padrões das atividades. Além disso, considerou-se que o tempo de ciclo segue uma distribuição triangular, na qual existe uma moda "c", um valor mínimo "a" e um valor máximo "b" representado por $\mathrm{T}(\mathrm{a} ; \mathrm{c} ; \mathrm{b})$ na Tabela 1. Os parâmetros da Tabela 1 foram considerados constantes para todos os cenários simulados. Por outro lado, os valores apresentados na Tabela 2 correspondem às variáveis modificadas no simulador a cada cenário proposto. 
Quadro 4 - Descrição dos cenários alternativos

\begin{tabular}{|c|c|c|c|}
\hline Proposta & O quê? & Por quê? & Como? \\
\hline Cf1 & $\begin{array}{l}\text { Modificação do layout } \\
\text { funcional para layout } \\
\text { celular por família }\end{array}$ & $\begin{array}{l}\text { Eliminar desperdícios de: } \\
\text { - Transporte; } \\
\text { - Movimentos } \\
\text { desnecessários; } \\
\text { - Espera. }\end{array}$ & $\begin{array}{l}\text { Construção do modelo considerando a } \\
\text { linearização do processo, diminuindo as } \\
\text { distâncias a ponto de eliminar as } \\
\text { movimentações desnecessárias do } \\
\text { operador, além do desperdício de } \\
\text { transporte do material por meio de } \\
\text { esteiras automáticas. }\end{array}$ \\
\hline Cf2 & $\begin{array}{l}\text { Diminuição do lote de } \\
\text { transferência/criação } \\
\text { do fluxo unitário }\end{array}$ & $\begin{array}{l}\text { Eliminar desperdícios de: } \\
\text { - Superprodução; } \\
\text { - Espera; } \\
\text { - Estoques. }\end{array}$ & $\begin{array}{l}\text { Adoção de um fluxo unitário do produto } \\
\text { através de todas as tarefas com o } \\
\text { objetivo de eliminar o tempo de espera e } \\
\text { acumulação de estoques de produtos em } \\
\text { processo. }\end{array}$ \\
\hline Cf3 & $\begin{array}{l}\text { Kaizens de } \\
\text { Qualidade/ Qualidade } \\
\text { na fonte/ defeito zero }\end{array}$ & $\begin{array}{l}\text { Eliminar desperdícios de: } \\
\text { - Produtos defeituosos. }\end{array}$ & $\begin{array}{l}\text { Sugestão de um ambiente no qual são } \\
\text { consideradas melhorias de qualidade no } \\
\text { processo por meio da introdução de } \\
\text { poka-yoke na célula estudada, impedindo } \\
\text { a produção de produtos defeituosos. } \\
\text { Com meta de reduzir em } 50 \% \text { os defeitos } \\
\text { nos processos de corte e montagem. }\end{array}$ \\
\hline
\end{tabular}

Fonte: Elaborado pelos autores

Tabela 1 - Parâmetros utilizados nas simulações

\begin{tabular}{lcc}
\hline Atividades & $\begin{array}{c}\text { Tempo de ciclo } \\
\text { (s/unid.) }\end{array}$ & $\begin{array}{c}\text { Capacidade } \\
\text { (unid./ciclo) }\end{array}$ \\
\hline Halogenação & $\mathrm{T}(45 ; 48 ; 52)$ & 3 \\
Prensa Térmica 1 & $\mathrm{T}(41 ; 45 ; 49)$ & 3 \\
Prensa Térmica 2 & $\mathrm{T}(41 ; 45 ; 49)$ & 3 \\
Corte & $\mathrm{T}(12 ; 15 ; 18)$ & 1 \\
Inspeção 1 & $\mathrm{T}(11 ; 15 ; 18)$ & 1 \\
Montagem & $\mathrm{T}(12 ; 14 ; 18)$ & 1 \\
Inspeção 2 & $\mathrm{T}(10 ; 15 ; 18)$ & 1 \\
\hline
\end{tabular}

Fonte: Elaborado pelos autores

A simulação foi conduzida durante um período de 59 horas para cada cenário, sendo 15 horas de warm-up da célula, realizado com o intuito de preencher todos os processos com estoques e observar a posteriori os cenários trabalhando em regime normal de trabalho. Assim foram 44 horas úteis rodadas, equivalente a um turno funcionando durante uma semana. Os resultados da simulação dos cenários foram sintetizados na Tabela 3. 
Tabela 2 - Variáveis utilizadas nas simulações

\begin{tabular}{|c|c|c|c|c|c|c|c|c|c|c|}
\hline Cenário & Variável & 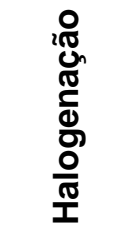 & 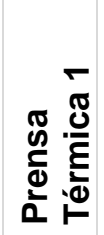 & 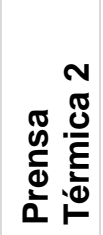 & 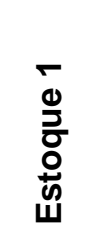 & 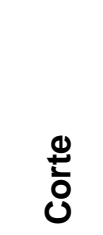 & 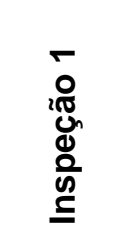 & 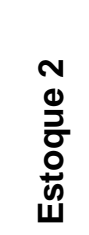 & 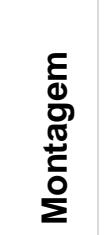 & 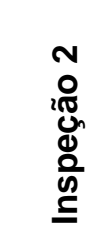 \\
\hline \multirow{5}{*}{$\begin{array}{c}\text { EA } \\
\text { (Estado } \\
\text { Atual) }\end{array}$} & Disponibilidade & $100 \%$ & $90 \%$ & $90 \%$ & - & $95 \%$ & $100 \%$ & - & $95 \%$ & $100 \%$ \\
\hline & $\begin{array}{l}\text { Tamanho do lote de } \\
\text { entrada }\end{array}$ & 480 & 3 & 3 & - & 480 & 1 & - & 480 & 1 \\
\hline & Tamanho do lote de saída & 3 & 3 & 480 & - & 1 & 480 & - & 1 & 1 \\
\hline & Estoque intermediário? & - & - & - & Sim & - & - & Sim & - & - \\
\hline & Taxa de defeito & - & - & - & - & $6,2 \%$ & - & - & - & $0,6 \%$ \\
\hline Cf1 & Estoque intermediário? & - & - & - & Não & - & - & Não & - & - \\
\hline \multirow{2}{*}{ Cf2 } & $\begin{array}{l}\text { Tamanho do lote de } \\
\text { entrada }\end{array}$ & 3 & 3 & 3 & - & 1 & 1 & - & 1 & 1 \\
\hline & Tamanho do lote de saída & 3 & 3 & 3 & - & 1 & 1 & - & 1 & 1 \\
\hline \multirow{2}{*}{ Cf3 } & Disponibilidade & $100 \%$ & $98 \%$ & $98 \%$ & - & $95 \%$ & $100 \%$ & - & $95 \%$ & $100 \%$ \\
\hline & Taxa de defeito & - & - & - & - & $3,1 \%$ & - & - & - & $0,3 \%$ \\
\hline
\end{tabular}

Fonte: Elaborado pelos autores

Tabela 3 - Resultados das simulações

\begin{tabular}{|c|c|c|c|c|c|c|c|c|}
\hline & EA & Cf1 & Cf2 & Cf3 & (Cf1-EA) & (Cf2-Cf1) & (Cf3-Cf2) & (Cf3-EA) \\
\hline Total de saídas (unid.) & 9184 & 9173 & 9179 & 9468 & $-0,1 \%$ & $0,1 \%$ & $3,1 \%$ & $3,1 \%$ \\
\hline Total em processo (unid.) & 2058 & 1010 & 40 & 70 & $-50,9 \%$ & $-96,0 \%$ & $75,0 \%$ & $-96,6 \%$ \\
\hline $\begin{array}{l}\text { Tempo médio no sistema } \\
\text { (min) }\end{array}$ & 499,25 & 254,70 & 12,56 & 11,35 & $-49,0 \%$ & $-95,1 \%$ & $-9,6 \%$ & $-97,7 \%$ \\
\hline $\begin{array}{l}\text { Tempo médio de espera } \\
\text { no sistema (min) }\end{array}$ & 264,82 & 132,60 & 0,20 & 0,06 & $-49,9 \%$ & $-99,8 \%$ & $-70,0 \%$ & $-100,0 \%$ \\
\hline $\begin{array}{l}\text { Tempo médio em } \\
\text { operação (min) }\end{array}$ & 3,32 & 3,32 & 3,32 & 3,32 & $0,0 \%$ & $0,0 \%$ & $0,0 \%$ & $0,0 \%$ \\
\hline $\begin{array}{l}\text { Tempo médio blocked } \\
\text { (min) }\end{array}$ & 230,00 & 118,58 & 8,88 & 7,79 & $-48,4 \%$ & $-92,5 \%$ & $-12,3 \%$ & $-96,6 \%$ \\
\hline $\begin{array}{l}\text { Produtos defeituosos } \\
\text { (unid.) }\end{array}$ & 688 & 654 & 641 & 297 & $-4,9 \%$ & $-2,0 \%$ & $-53,7 \%$ & $-56,8 \%$ \\
\hline Mão-de-obra direta & 13 & 12 & 12 & 12 & $-7,7 \%$ & $0,0 \%$ & $0,0 \%$ & $-7,7 \%$ \\
\hline Mão-de-obra indireta & 2 & 1 & 1 & 1 & $-50,0 \%$ & $0,0 \%$ & $0,0 \%$ & $-50,0 \%$ \\
\hline Produtividade (unid./Hh) & 13,90 & 16,03 & 16,04 & 16,55 & $15,2 \%$ & $0,1 \%$ & $3,1 \%$ & $19,0 \%$ \\
\hline
\end{tabular}

Legenda: $\mathrm{EA}$ = estado atual; (Cfn-EA) = comparação percentual dos cenários futuros com o estado atual.

Fonte: Elaborado pelos autores

De acordo com os resultados apresentados na Tabela 3 observa-se que, com a implementação da linearização dos processos (Cf1) e a criação do fluxo unitário (Cf2), houve uma minimização gradativa do total de unidades em processo, do 
tempo médio no sistema (tempo de atravessamento), do tempo médio de espera e do tempo médio blocked (tempo que o material aguarda o processamento do lote inteiro para ser transferido). No terceiro cenário (Cf3), com a implementação da Gestão da Qualidade Zero Defeito, pode-se destacar, além dos indicadores citados, a redução significativa do total de produtos defeituosos.

Considerando que a perfeição e o zero defeito são estados teóricos, o Cf3 engloba ações viáveis no contexto da empresa, como a redução gradual do índice de produtos defeituosos do corte (de 6,2\% para 3,1\%) e da montagem (de 0,6\% para $0,3 \%$ ), além do aumento de disponibilidade e confiabilidade das prensas térmicas, todas por meio de inciativas dos Círculos de Controle da Qualidade (CCQs) existentes na empresa.

Por fim, observa-se que o cenário futuro 3 (Cf3), que engloba todas as ações propostas no mapa do estado futuro, apresenta uma melhoria de $19 \%$ na produtividade em relação ao estado atual (EA), devido a redução dos produtos defeituosos e da mão-de-obra.

O estudo de caso permitiu confirmar que a inclusão da simulação de eventos discretos na metodologia tradicional de aplicação do MFV traz vantagens significativas. O Quadro 5 apresenta algumas dessas vantagens.

De fato, a experiência adquirida com esta pesquisa permitiu enumerar as vantagens descritas no Quadro 5. Esses resultados corroboram com pesquisas semelhantes, como as de Oliveira, Corrêa e Nunes (2014) e Gurumurthy e Kodali (2011), que igualmente defendem o uso da simulação como uma forma de tornar o MFV mais eficaz em seu propósito.

\section{CONCLUSÕES}

Por meio da elaboração do Mapeamento do Fluxo de Valor (MFV) do estado atual foi possível visualizar todo o processo produtivo e identificar as fontes de desperdícios do processo. A aplicação confirmou a literatura permitindo reafirmar que esta técnica é de extrema importância para a melhor compreensão do processo como um todo, além de adotar uma linguagem comum para representar as atividades. 
Quadro 5 - Vantagens da inclusão da simulação no MFV tradicional

\begin{tabular}{|l|l|l|}
\cline { 2 - 3 } \multicolumn{1}{l|}{} & MFV tradicional & MFV com Simulação \\
\hline Análise do estado atual & $\begin{array}{l}\text { Limitada aos dados atuais que } \\
\text { estão disponíveis na empresa } \\
\text { ou que são coletados para o } \\
\text { MFV, mas com restrições para a } \\
\text { obtenção de indicadores de } \\
\text { desempenho. }\end{array}$ & $\begin{array}{l}\text { Permite gerar indicadores de } \\
\text { desempenho do estado atual que } \\
\text { nem sempre estão disponíveis e que } \\
\text { não são medidos regularmente pela } \\
\text { empresa (ex.: capacidade, } \\
\text { utilização, produtividade, etc.). }\end{array}$ \\
\hline $\begin{array}{l}\text { Transição para o estado } \\
\text { futuro }\end{array}$ & Baseada na intuição do analista. & $\begin{array}{l}\text { Pode-se testar várias configurações } \\
\text { com dados reais (históricos) ou } \\
\text { hipotéticos. }\end{array}$ \\
\hline $\begin{array}{l}\text { Implementação do estado } \\
\text { futuro }\end{array}$ & $\begin{array}{l}\text { Abordagem de tentativa e erro } \\
\text { in loco, gerando custos e tempo } \\
\text { adicionais. }\end{array}$ & $\begin{array}{l}\text { A tentativa e erro ocorre de forma } \\
\text { virtual, gerando um esforço menor } \\
\text { (custo e tempo) para definir a } \\
\text { melhor alternativa a ser } \\
\text { implementada. }\end{array}$ \\
\hline Abordagem de melhoria & $\begin{array}{l}\text { A implantação do estado futuro } \\
\text { pode representar uma melhoria } \\
\text { radical que tende a criar uma } \\
\text { maior resistência à mudança. }\end{array}$ & $\begin{array}{l}\text { A simulação pode ajudar a definir } \\
\text { uma sequência incremental de } \\
\text { implementação do estado futuro, } \\
\text { permitindo prever os ganhos } \\
\text { parciais e conduzir a mudança em } \\
\text { um processo de melhoria contínua. }\end{array}$ \\
\hline
\end{tabular}

Fonte: Elaborado pelos autores

Além disso, com o levantamento dos tempos de agregação e não agregação de valor, conseguiu-se identificar as etapas do processo que mais desperdiçavam tempo com atividades que não agregam valor ao produto. Assim, visando uma maior produtividade pela redução dos desperdícios, foram propostas as implementações de algumas das técnicas, ferramentas e práticas adotadas pelo sistema Lean Manufacturing (LM).

A simulação dos cenários que contemplavam as mudanças no processo a fim de reduzir os desperdícios indicou que os três cenários, construídos com as melhorias de processo idealizadas, possibilitam a redução dos desperdícios identificados por meio do MFV do estado atual. Chama atenção o potencial de ganho de produtividade de até $19 \%$ caso a empresa implemente todas as práticas lean que foram propostas. Isto denota a efetividade das práticas lean no aumento da produtividade e na redução da quantidade de materiais em processo e do tempo médio do produto no sistema.

Além desses resultados, denota-se ainda que a simulação se mostrou uma técnica essencial para complementar o MFV, à medida que possibilitou testar 
cenários futuros, demonstrando eficácia no direcionamento do plano de ação e da construção do estado futuro do processo.

De acordo com Gurumurthy e Kodali (2011), a simulação permite aos gestores enxergar o desempenho dos sistemas de produção com a adoção do lean antes de serem executadas. Este trabalho confirmou a afirmação desses autores ao reconhecer que uma das vantagens da simulação é o fato de se considerar cenários diversos e observar o comportamento do processo diante das mudanças propostas e, também, antever problemas de operacionalização. Como resultado, tem-se um menor tempo para a tomada de decisão e envolvimento de menores custos operacionais antes de se adotar as ações que impactem o processo. A possibilidade de testar alternativas antes da implementação reduz o impacto que a abordagem tradicional implica, na qual custo e tempo podem ser desperdiçados no ajuste in loco de soluções avaliadas precariamente.

Como proposta para futuros trabalhos, recomenda-se 0 estudo mais aprofundado dos impactos do Lean Manufacturing no sistema através de modelos mais robustos de simulação, com o objetivo de abranger mais variáveis, os outros processos da empresa e, consequentemente, se aproximar cada vez mais da realidade. Sugere-se também a análise da implementação das ações propostas in loco, comparando dos resultados reais com os resultados obtidos em simulação.

\section{REFERÊNCIAS}

ABDULMALEK, F. A.; RAJGOPAL, J. Analyzing the benefits of lean manufacturing and value stream mapping via simulation: a process sector case study. International Journal of Production Economics, v. 107, n. 1, p. 223-236, 2007.

http://dx.doi.org/doi:10.1016/i.ijpe.2006.09.009

ALI, N. B.; PETERSEN, K.; FRANÇA, B. B. N. Evaluation of simulation-assisted value stream mapping for software product development: two industrial cases. Information and Software Technology, v. 68, p. 45-61, 2015. http://dx.doi.org/doi:10.1016/j.infsof.2015.08.005

BHAMU, J.; SANGWAN, K. S. Lean manufacturing: literature review and research issues. International Journal of Operations \& Production Management, v. 34, n. 7, p. 876-940, 2014. http://dx.doi.org/doi:10.1108/IJOPM-08-2012-0315

CERVO, A.; BERVIAN, P.; SILVA, R. Metodologia científica. 6.ed. São Paulo: Pearson Prentice Hall, 2007. 
DAL FORNO, A. J. et al. Value stream mapping: a study about the problems and challenges found in the literature from the past 15 years about application of lean tools. The

International Journal of Advanced Manufacturing Technology, v. 72, n. 5, p. 779-790, 2014. http://dx.doi.org/10.1007/s00170-014-5712-z

GURUMURTHY, A.; KODALI, R. Design of lean manufacturing systems using value stream mapping with simulation: a case study. Journal of Manufacturing Technology

Management, v. 22, n. 4, p. 444-473, 2011.http://dx.doi.org/10.1108/17410381111126409

JASTI, N. K. V.; SHARMA, A. Lean manufacturing implementation using value stream mapping as a tool: a case study from auto components industry. International Journal of Lean Six Sigma, v. 5, n. 1, p. 89-116, 2014. http://dx.doi.org/10.1108/lJLSS-04-2012-0002

LASA, I. S.; CASTRO, R.; LABURU, C. O. Extent of the use of lean concepts proposed for a value stream mapping application. Production Planning \& Control, v. 20, n. 1, p. 82-98, 2009. http://dx.doi.org/10.1080/09537280802685322

LIAN, Y.-H.; VAN LANDEGHEM, H. Analysing the effects of lean manufacturing using a value stream mapping-based simulation generator. International Journal of Production Research, v. 45, n. 13, p. 3037-3058, 2007. http://dx.doi.org/10.1080/00207540600791590

MARODIN, G. A.; SAURIN, T. A. Implementing lean production systems: research areas and opportunities for future studies. International Journal of Production Research, v. 51, n. 22, p. 6663-6680, 2013. http://dx.doi.org/10.1080/00207543.2013.826831

MCDONALD, T.; VAN AKEN, E. M.; RENTES, A. F. Utilising simulation to enhance value stream mapping: a manufacturing case application. International Journal of Logistics, v. 5, n. 2, p. 213-232, 2002. http://dx.doi.org/10.1080/13675560210148696

MONDEN, Y. Sistema Toyota de produção: uma abordagem integrada ao just-in-time. 4.ed. Porto Alegre: Bookman, 2015.

OLIVEIRA, R. B. M.; CORRÊA, V. A.; NUNES, L. E. N. P. Mapeamento do fluxo de valor em um modelo de simulação computacional. Revista Produção Online, v. 14, n. 3, p. 837-861, 2014. http://dx.doi.org/10.14488/1676-1901.v14i3.1461

PETTERSEN, J. Defining lean production: some conceptual and practical issues. The TQM Journal, v. 21, n. 2, p. 127-142, 2009. http://dx.doi.org/10.1108/17542730910938137

ROTHER, M.; SHOOK, J. Aprendendo a enxergar: mapeando o fluxo de valor para agregar valor e eliminar o desperdício. São Paulo: Lean Institute Brasil, 2003.

SERRANO, I.; OCHOA, C.; CASTRO, R. Evaluation of value stream mapping in manufacturing system redesign. International Journal of Production Research, v. 46, n. 16, p. 4409-4430, 2008. http://dx.doi.org/10.1080/00207540601182302

SHINGO, S. Sistema Toyota de Produção: do ponto de vista da engenharia de produção. Porto Alegre: Bookman, 1996.

VINODH, S.; ARVIND, K. R.; SOMANAATHAN, M. Application of value stream mapping in an Indian camshaft manufacturing organisation. Journal of Manufacturing Technology Management, v. 21, n. 7, p. 888-900, 2010. http://dx.doi.org/10.1108/17410381011077973 
WOMACK, J. P.; JONES, D. T.; ROSS, D. The machine that changed the world. New York, NY: Rawson Associates, 1990.

YANG, T. et al. The optimization of total laboratory automation by simulation of a pullstrategy. Journal of Medical Systems, v. 39, n. 1, p. 1-12, 2015.

http://dx.doi.org/10.1007/s10916-014-0162-6

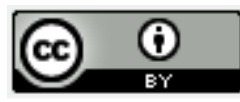

Artigo recebido em 28/09/2015 e aceito para publicação em 06/12/2015

DOI: http://dx.doi.org/ 10.14488/1676-1901.v16i1.2183

Revista Produção Online, Florianópolis, SC, v. 16, n. 1, p. 366-392, jan./mar. 2016. 